\title{
Predicting Deliberate Self-Harm in Adolescents: A Six Month Prospective Study
}

\author{
Rory C. O'Connor, PhD, Susan Rasmussen, PhD, and Keith Hawton, DSc
}

Few studies have investigated the extent to which psychosocial/psychological factors are associated with the prediction of deliberate self-harm (DSH) among adolescents. In this study, 737 pupils aged 15-16 years completed a lifestyle and coping survey at time one and 500 were followed up six months later. Six point two percent of the respondents $(n=31)$ reported an act of DSH between Time 1 and Time 2. In multivariate analyses, worries about sexual orientation, history of sexual abuse, family DSH, anxiety, and self-esteem were associated with repeat DSH during the course of the study, but history of sexual abuse was the only factor predictive of first-time DSH. The findings suggest that school-based programs focused on how young people cope with psychosocial stressors may offer promise.

Deliberate self-harm (DSH) represents one of the leading causes of admission of adolescents to general hospitals and is a major health and social problem in this age group (Berman, Jobes, \& Silverman, 2005; O'Loughlin \& Sherwood, 2005). In addition, retrospective and prospective studies of self-harmers and suicide attempters point to their increased risk of future suicide attempts and completed suicide (Fergusson, Horwood, Ridder, \& Beautrais, 2005; Goldacre \& Hawton, 1985; Hawton \& Fagg, 1988; Hawton, Houston, \& Shepperd, 1999; Hawton, Zahl,

Rory C. O'Connor and Susan Rasmussen are with the University of Stirling, Scotland; and Keith Hawton is with the University of Oxford, England.

This study was funded by Choose Life Stirling (National Suicide Prevention Strategy and Action Plan for Scotland) and University of Stirling, Scotland.

Address correspondence to Dr. Rory C. O'Connor, Suicidal Behavior Research Group, Department of Psychology, University of Stirling, Stirling, Scotland, FK9 4LA; E-mail: ro2@stir. ac.uk
\& Weatherall, 2003; O'Connor, Sheehy, \& O'Connor, 1999).

It is also accepted that DSH which results in hospital admission is only the tip of the iceberg (see Appleby, Amos, Doyle, Tomenson, \& Woodman, 1996; Garrison, McKeown, Valois, \& Vincent, 1993; Sourander, Helstela, Haavisto, \& Bergoth, 2001). For example, in the US, the Youth Risk Behavior Survey showed that of the $8.5 \%$ of adolescents who reported attempted suicide in the previous year, only $2.9 \%$ presented to a health professional (Centers for Disease Control and Prevention, 2004; see also Choquet \& Ledoux, 1994; Kann et al., 2000). Similarly in the UK, in a survey of over 6,000 adolescents, Hawton, Rodham, Evans, and Weatherall (2002) found that only $12.6 \%$ of the reported DSH episodes resulted in presentation to hospital. Therefore, given the public concern about DSH in adolescents, it is perhaps surprising that, with one exception (Meltzer, Harrington, Goodman, \& Jenkins, 2001), until the development of the Child and Adolescent Self-harm in Europe survey (CASE; see Hawton, Rodham, \& Evans, 2006), there had been no large-scale commu- 
nity-based surveys of adolescent DSH in the UK.

The aim of the CASE study was to develop a measure of DSH that could be administered in several European countries (and Australia) to determine (i) the prevalence of DSH among adolescents throughout Europe (and Australia) and (ii) the factors associated with DSH. The CASE questionnaire was devised following a review of the known risk factors associated with DSH. Indeed, its aim was to identify the factors associated with deliberate self-harm. These factors include demographic factors, stressors (e.g., bullying), social influences (e.g., self-harm by friends), personality factors (e.g., impulsivity), coping as well as indices of psychological well-being. The choice of items included in the modified CASE questionnaire (employed herein) was guided by the diathesis-stress framework (which posits that psychological/biological vulnerabilities are most deleterious under stress; Joiner \& Rudd, 1995) and the Theory of Planned Behavior (which incorporates social pressures into the prediction of risk behaviors; Ajzen, 1991). Consequently, we included additional personality (e.g., perfectionism) and social factors (group norms) which are known to be associated with suicide risk (O'Connor, 2007; O'Connor, Armitage, \& Gray, 2006; O’Connor \& Cassidy, 2007).

A review of the published literature reveals that similar rates of DSH were found in most of the countries in the CASE study, including England (Hawton et al., 2002), Ireland (Sullivan, Arensman, Keeley, Corcoran, \& Perry, 2004), Norway (Ystgaard, Reinholdt, Husbym, \& Mehlum, 2003), Belgium (Hawton, Rodham, \& Evans, 2006), and Australia (De Leo \& Heller, 2004), but lower rates in The Netherlands and Hungary (Hawton et al., 2006). In addition, we recently reported retrospective prevalence rates for Scotland and found similar rates to those in England, Ireland, Norway, Belgium, and Australia (O'Connor, Rasmussen, Miles, \& Hawton, 2009).

In the present study, however, we extended the methodology used in the CASE study (which was cross-sectional) by: (i) conducting a short-term prospective study of a sub-sample of our Scottish study and by (ii) including additional psychosocial factors known to be important in the etiology of self-harm, namely optimism, group norms (social pressure to act in a particular way) and social perfectionism (perceived expectations from others; O'Connor, 2007; O'Connor et al., 2006; O'Connor \& Cassidy, 2007). In short, our aims were two-fold: (1) to determine the prevalence of DSH prospectively over a six-month period and (2) to investigate the factors associated with prospective DSH.

\section{METHOD}

\section{Participants}

We recruited 737 adolescents from three local authority secondary schools in Central Scotland to participate in a "Lifestyle and Coping" study. This is part of a larger study $(n=2008)$ of the prevalence of DSH which is reported elsewhere (O'Connor, Rasmussen, Miles, \& Hawton, 2008). The proportion of females to males in this sub-sample was higher than that in the larger study, Chi = $8.19, d f=2, p<.05$ and the respondents were a little younger in the present study compared to the latter study $(M=15.2(S D=.72)$ vs. $M=15.4(S D=.82 ; t(1998)=6.33, p<.001)$. The selection of schools for the follow-up was made on pragmatic grounds. The larger study incorporated schools from two Local Authorities, however, there was only funding to follow up schools from one of the Local Authorities. Within this Local Authority, three of the schools agreed to participate in the follow-up. There were 367 females and 369 males with an overall mean age of 15.2 years $(S D=.7)$. The boys $(M=15.2, S D=.7)$ and girls $(M=15.2, S D=.8)$ did not differ significantly in age, $t(733)=.64$, ns. At Time 1 , all participants completed a modified version of the questionnaire used in the CASE survey, as outlined below. At Time 2, 6 months later, participants were asked to complete the modified CASE survey question- 
naire again. The respondents were all in classes in which at least $90 \%$ of the young people were aged 15 to 16 years.

\section{Procedure}

The aim of the study was explained to the Head Teacher or their designate. Parents were informed of the project by letter and asked to notify the school if they did not want their child to participate. Two or three weeks before data collection, the nature of participation was explained in detail to the teachers. On the day of participation pupils were given the choice of opting out and not participating.

We had obtained ethical approval from the Stirling University Psychology Department ethics committee. Our study adhered to the British Psychological Society's ethical guidelines (British Psychological Society, 2004) and the British Educational Research Association's guidelines (British Educational Research Association, 1992). To highlight that the survey was anonymous, all pupils were provided with an envelope in which to insert and seal their completed questionnaires. The sealed envelopes were opened only by members of the research team. Each participant was also given an information sheet to take away with them which included telephone/ postal and electronic contacts for useful support organizations. To ensure anonymity but to allow for follow-up, respondents were asked to answer a series of questions at both time points which generated a unique reference code.

\section{ASSESSMENT OF PARTICIPANTS}

A modified version of the Lifestyle and Coping Questionnaire used in Oxford for the Child and Adolescent Self-harm in Europe (CASE) survey was used with permission (see O'Connor, Rasmussen, Miles, \& Hawton, 2009 for full details; see also Hawton et al., 2002). This is an anonymous self-report questionnaire, which takes approximately 30 minutes to complete. The original survey was developed in collaboration with experts in school-based studies and underwent extensive piloting in schools and an adolescent psychiatric unit.

The questionnaire included items on demographic characteristics (i.e., sex, age, ethnicity), lifestyle (e.g., frequency of alcohol use), life events/problems (e.g., history of sexual abuse) and social influences (e.g., selfharm by friends). In addition, participants completed the following measures:

Deliberate Self-Harm. Deliberate selfharm was recorded if a respondent answered yes to the following question "have you ever deliberately taken an overdose (e.g., pills or other medication) or tried to harm yourself in some other way (such as cut yourself)?" Consistent with other studies in Europe (e.g., Schmidtke et al., 1996) and elsewhere (e.g., Carter, Reith, Whyte, \& McPherson, 2005), the definition of DSH employed herein includes intentional self-injury and self-poisoning, irrespective of motivation or suicidal intent. Such an inclusive definition embodies the often mixed nature of self-harm intentions (Bancroft, Skrimshire, \& Simkin, 1976; Hjelmeland et al., 2002) and the assertion that suicidal intent is a dimensional rather than a binary phenomenon (Harriss, Hawton, \& Zahl, 2005). However, see Silverman, Berman, Sanddal, O'Carroll, \& Joiner (2007a,b) for further discussion of the difficulties around determining suicidal intent and a revised nomenclature for the study of suicide and suicidal behaviors. If participants reported DSH, they were asked when they had last self-harmed and how often they had selfharmed in the past. If a participant answered "yes" to the DSH question, they were asked to describe what they did on that occasion. Classification of an episode as DSH was based on the agreed CASE definitions (see Hawton et al., 2006). As participants were asked the DSH questions at Time 1 and Time 2, we were able to ascertain whether (i) they had self-harmed for the first-time between Time 1 and Time 2 (i.e., first-timers) 
or (ii) they had self-harmed again between Time 1 and Time 2 (i.e., repeaters).

Depression and Anxiety. These were assessed with the Hospital Anxiety and Depression Scale (HADS; Zigmond \& Snaith, 1983; White, Leach, Sims, Atkinson, \& Cottrell, 1999) which consists of 14 questions, seven corresponding to the anxiety subscale (e.g., Worrying thoughts go through my mind) and seven corresponding to the depression subscale (e.g., I have lost interest in my appearance). Items are rated on a $0-3$ point scale indicating strength of agreement with each item. Internal consistency was .64 and .76 for depression and anxiety, respectively. The HADS is a reliable and valid measure of affect (Bjelland, Dahl, Haug, \& Necklemann, 2002).

Optimism. Optimism was measured by the Life Orientation Test-Revised (LOTR; Scheier, Carver, \& Bridges, 1994). It is a 10-item questionnaire which measures optimism through questions such as "In uncertain times, I usually expect the best." It contains 4 filler questions and responses range from I agree a lot (5) to I disagree a lot (1). The LOT is valid and it has good temporal stability over 4 weeks $(r=.79), 4$ months $(r=$ $.68)$, and 12 months $(r=.60$; Scheier \& Carver, 1985; Scheier, Carver, \& Bridges, 1994). Cronbach's alpha $=.78$.

Self-Esteem. Self-esteem was measured using a short version of Robson's Selfconcept Scale (Robson, 1989). Respondents are asked to indicate how much they agree or disagree with each of eight statements including "Everyone seems much more confident and contented than me" from 0 to 3 . The Self-Concept scale is reliable and valid (Addeo, Greene, \& Geisser, 1994; Robson, 1989) and is internally consistent in this sample $($ Cronbach's alpha $=.74)$.

Impulsivity. A shortened version of the Plutchik Impulsivity Scale (PIS-short; Plutchik, van Praag, Picard, Conte, \& Korn, 1989) was used to measure impulsivity. This measure includes six items (e.g., I do things on the spur of the moment). Respondents are asked to indicate how often they feel/behave from almost never (0) to very often (3). Although the original 15 -item version of the PIS has been shown to be internally consistent (alpha $=.73$; Plutchik et al., 1989), Cronbach's alpha in the present sample was low (alpha $=.57)$.

Social Perfectionism. The social perfectionism subscale of the Child and Adolescent Perfectionism Scale (CAPS; Flett, Hewitt, Boucher, Davidson, \& Munro, 1997) was employed to tap the degree of belief by individuals that others hold unrealistically high expectations of one's behavior and that they would only be satisfied with these standards (e.g., Other people always expect me to be perfect). Respondents were asked to indicate the extent to which the statements are false (1) or very true (5). The social perfectionism scale of the CAPS has good internal consistency and has been shown to be invariant across gender and time (across 6 months; O'Connor, Dixon, \& Rasmussen, 2009). The scale had good internal consistency (Cronbach's $\alpha=.86$ ).

\section{ANALYSES}

Logistic regression analyses and Chisquare tests were used to investigate associations between DSH and associated variables. Crude odds ratios and confidence intervals were obtained from the univariate logistic regression analyses. Adjusted odds ratios were obtained from multivariate logistic regression. Only those variables which were associated with DSH in the univariate analyses were included in the multivariate analyses.

1. As there are relatively low expected frequencies in some of the cells, we also conducted a series of nonparametric tests (Kruskall-Wallis tests). With only one exception, smoking; the nonparametic test yielded a significant association $(p<$ $.043)$ whereas the parametric test did not $(p<.052)$, these analyses yielded the same findings as those obtained via the multinomial logistic regression analyses. In the interests of parsimony however, we only report the logistic regression analyses herein. 
Backward selection was used to determine the factors which were most important statistically in distinguishing those who did and did not engage in DSH between Time 1 and Time 2.

\section{RESULTS}

At Time 1, we recruited 737 respondents and at Time 2, six months later, we followed up 515 of these young people thereby yielding a response rate of $70 \%$. We had to exclude an additional 15 respondents as it was not possible to determine whether they had self-harmed or not between Time 1 and Time 2. Therefore, the main analyses are based on the 500 respondents who completed measures at Time 1 and Time 2 and for whom we can ascertain self-harming status during the course of the study. With the exception of impulsivity, those who completed Time 2 were similar to those who did not in terms of the psychological measures (i.e., depression, anxiety, optimism, self-esteem, and social perfectionism; range of $t=.11-$ 1.83 , ns). Those who did not complete the survey at time two were more impulsive $(M=8.64, S D=3.01)$ than those who did, $(M=8.03, S D=2.83 ; t(735)=2.66, p<.01$. There were similar proportions of males/females in each group although those who did not complete Time $2(M=15.36, S D=.74)$ were significantly older than those who did $(M=15.13, S D=.69)$.

\section{PREVALENCE OF DELIBERATE SELF-HARM BETWEEN TIME 1 AND TIME 2}

During the six months follow-up period, as expected, the vast majority of respondents did not self-harm $(93.8 \% ; n=469)$. However, 31 respondents (6.2\%) reported deliberate self-harm between Time 1 and Time 2, with 13 (2.6\%) self-harming for the first time (i.e., first-timers) and 18 (3.6\%) reporting that they had self-harmed again (i.e., repeaters). The majority of self-harmers were female $(65 \% ; 20 / 31)$ and females were particularly overrepresented in the repeater group (odds ratio $=5.81$, confidence interval 1.66 to $20.32, p<.01)$.

\section{FACTORS ASSOCIATED WITH DELIBERATE SELF-HARM BETWEEN TIME 1 AND TIME 2}

Those who self-harmed for the firsttime between Time 1 and Time 2 were significantly more likely to have reported a history of sexual abuse at Time 1 than those who did not self-harm (see Table 1). In addition, the first-timers were more depressed and anxious and had lower self-esteem than those who did not self-harm. The first-timers also reported that their friends and peers were more positive about self-harm than the nonself-harmers, i.e., they had stronger DSH group norms. Group norms are defined as the attitudes of peers and friends towards DSH.

The adolescents who repeated DSH were significantly more likely to be female, not to be living with both parents and to have parents who had divorced or separated. Compared with those who did not self-harm, they were also significantly more likely to report being drunk and to have used drugs in the past year. They were also more likely to have reported being bullied, to have been sexually abused, to have concerns about their sexuality and have had serious boy/girlfriend problems at Time 1. Social influence factors were also evident. Thus the repeaters were significantly more likely to know family and

2. At Time 1 and Time 2, with the exception of 2 (Time 1) and 3 (Time 2) participants (who did not provide a DSH description), respectively, all participants who reported DSH met the CASE DSH criteria based on their descriptions of the DSH episodes. To maximize statistical power and because, in the larger Scottish sample some participants indicated that they chose not to disclose details of the DSH episode for personal reasons, we retained all those who reported a DSH episode in the analyses (i.e., 31). 
TABLE 1

Univariate Multinomial Logistic Regression Analyses of the Association of DSH Status (i.e., First-Time

Self-Harmers $(\mathrm{N}=13)$ and Repeat Self-Harmers $(\mathrm{N}=18)$ Versus Those Who Did Not Report DSH

Between Time 1 and Time 2, N = 469) and the Other Variables

\begin{tabular}{|c|c|c|c|c|c|c|c|c|c|c|c|}
\hline & \multirow[b]{2}{*}{$N$} & \multicolumn{5}{|c|}{$\begin{array}{c}\text { First-time DSH versus } \\
\text { No DSH between T1 and T2 }\end{array}$} & \multicolumn{5}{|c|}{$\begin{array}{c}\text { Repeat DSH versus } \\
\text { No DSH between T1 and T2 }\end{array}$} \\
\hline & & $\begin{array}{l}\%(\Lambda \\
\text { self- }-\end{array}$ & $\begin{array}{l}\text { V) who } \\
\text { harmed }\end{array}$ & $\begin{array}{c}\text { Odds } \\
\text { ratio }\end{array}$ & $95 \% \mathrm{CI}$ & $P$ values & $\begin{array}{l}\%(1 \\
\text { self- }\end{array}$ & $\begin{array}{l}N) \text { who } \\
\text {-harmed }\end{array}$ & $\begin{array}{l}\text { Odds } \\
\text { ratio }\end{array}$ & $95 \% \mathrm{CI}$ & $P$ values \\
\hline \multicolumn{12}{|l|}{ Sex } \\
\hline Male & 263 & 3.0 & (8) & 1.00 & & & 1.1 & (3) & 1.00 & & \\
\hline Female & 237 & 2.1 & $(5)$ & .73 & $.23-2.25$ & .579 & 6.3 & $(15)$ & 5.81 & $1.66-20.32$ & .006 \\
\hline \multicolumn{12}{|c|}{ Living with both parents: } \\
\hline Yes & 363 & 2.5 & $(9)$ & 1.00 & & & 2.2 & $(8)$ & 1.00 & & \\
\hline No & 136 & 2.9 & (4) & 1.26 & $.38-4.17$ & .704 & 7.4 & $(10)$ & 3.55 & $1.37-9.19$ & .009 \\
\hline \multicolumn{12}{|c|}{$\begin{array}{c}\text { Divorced/separated } \\
\text { parents* }\end{array}$} \\
\hline No & 372 & 3.0 & $(11)$ & 1.0 & & & 2.2 & $(8)$ & 1.00 & & \\
\hline Yes & 128 & 1.6 & (2) & .55 & $.12-2.53$ & .446 & 7.8 & (10) & 3.80 & $1.47-9.87$ & .006 \\
\hline \multicolumn{12}{|l|}{ Smoking $\dagger$} \\
\hline No & 437 & 2.5 & $(11)$ & 1.00 & & & 3.0 & $(13)$ & 1.00 & & \\
\hline Yes & 62 & 3.2 & (2) & 1.37 & $.30-6.32$ & .691 & 8.1 & $(5)$ & 2.89 & $.99-8.41$ & .052 \\
\hline \multicolumn{12}{|c|}{ Alcohol use $\ddagger$} \\
\hline No & 174 & 1.7 & (3) & 1.00 & & & 2.9 & $(5)$ & 1.00 & & \\
\hline Yes & 319 & 3.1 & $(10)$ & 1.87 & $.51-6.89$ & .347 & 4.1 & (13) & 1.46 & $.51-4.16$ & .481 \\
\hline \multicolumn{12}{|c|}{ History of being drunk $\$$} \\
\hline No & 203 & 2.5 & $(5)$ & 1.00 & & & 1.5 & (3) & 1.00 & & \\
\hline Yes & 295 & 2.7 & (8) & 1.15 & $.37-3.60$ & .812 & 5.1 & $(15)$ & 3.59 & $1.02-12.55$ & .046 \\
\hline \multicolumn{12}{|c|}{ Any drug use $§$} \\
\hline No & 404 & 2.7 & $(11)$ & 1.00 & & & 2.7 & $(11)$ & 1.00 & & \\
\hline Yes & 96 & 2.1 & (2) & .80 & $.17-3.67$ & .772 & 7.3 & $(7)$ & 2.80 & $1.05-7.41$ & .039 \\
\hline \multicolumn{12}{|l|}{ Bullying* } \\
\hline No & 346 & 2.6 & (9) & 1.00 & & & 2.3 & (8) & 1.00 & & \\
\hline Yes & 152 & 2.6 & (4) & 1.06 & $.32-3.49$ & .924 & 6.6 & (10) & 2.98 & $1.15-7.71$ & .024 \\
\hline \multicolumn{12}{|c|}{ Physical abuse* } \\
\hline No & 482 & 2.7 & (13) & 1.00 & & & 16 & $(3.3)$ & 1.00 & & \\
\hline Yes & 15 & 0 & $(0)$ & 0.01 & - & - & 13.3 & (2) & 4.36 & $.91-20.94$ & .066 \\
\hline \multicolumn{12}{|c|}{ Sexual abuse* } \\
\hline No & 487 & 2.3 & (11) & 1.00 & & & 2.9 & (14) & 1.00 & & \\
\hline Yes & 13 & 15.4 & (2) & 12.00 & $2.23-64.48$ & .004 & 30.8 & (4) & 18.86 & $4.95-71.92$ & .001 \\
\hline \multicolumn{12}{|c|}{ Sexual orientation worries* } \\
\hline No & 475 & 2.5 & $(12)$ & 1.00 & & & 2.7 & $(13)$ & 1.00 & & \\
\hline Yes & 24 & 4.2 & (1) & 2.08 & $.26-16.91$ & .492 & 20.8 & $(5)$ & 9.62 & $3.09-29.88$ & .001 \\
\hline \multicolumn{12}{|c|}{ Trouble with Police* } \\
\hline No & 353 & 2.5 & $(9)$ & 1.00 & & & 3.7 & $(13)$ & 1.00 & & \\
\hline Yes & 147 & 2.7 & (4) & 1.07 & $.32-3.52$ & .916 & 3.4 & $(5)$ & .92 & $.32-2.64$ & .880 \\
\hline \multicolumn{12}{|c|}{$\begin{array}{l}\text { Serious boy/girlfriend } \\
\text { problems* }\end{array}$} \\
\hline No & 403 & 2.2 & (9) & 1.00 & & & 2.5 & $(10)$ & 1.00 & & \\
\hline Yes & 97 & 4.1 & (4) & 2.01 & $.60-6.67$ & .255 & 8.2 & $(8)$ & 3.61 & $1.39-9.43$ & .009 \\
\hline
\end{tabular}


TABLE 1

Continued

\begin{tabular}{|c|c|c|c|c|c|c|c|c|c|c|c|}
\hline & \multirow[b]{2}{*}{$N$} & \multicolumn{5}{|c|}{$\begin{array}{c}\text { First-time DSH versus } \\
\text { No DSH between T1 and T2 }\end{array}$} & \multicolumn{5}{|c|}{$\begin{array}{c}\text { Repeat DSH versus } \\
\text { No DSH between T1 and T2 }\end{array}$} \\
\hline & & $\begin{array}{l}\%(N \\
\text { self-h }\end{array}$ & $\begin{array}{l}\text { ) who } \\
\text { larmed }\end{array}$ & $\begin{array}{l}\text { Odds } \\
\text { ratio }\end{array}$ & $95 \% \mathrm{CI}$ & $P$ values & $\begin{array}{l}\%(I \\
\text { self- }-1\end{array}$ & $\begin{array}{l}\text { N) who } \\
\text { harmed }\end{array}$ & $\begin{array}{l}\text { Odds } \\
\text { ratio }\end{array}$ & $95 \% \mathrm{CI}$ & $P$ values \\
\hline \multicolumn{12}{|l|}{ Self-harm by friends* } \\
\hline No & 389 & 2.1 & (8) & 1.00 & & & 2.1 & (8) & 1.00 & & \\
\hline Yes & 111 & 4.5 & (5) & 2.43 & $.78-7.59$ & .127 & 9.0 & $(10)$ & 4.86 & $1.87-12.64$ & .001 \\
\hline \multicolumn{12}{|l|}{ Self-harm by family* } \\
\hline No & 449 & 2.4 & $(11)$ & 1.00 & & & 2.4 & $(11)$ & 1.00 & & \\
\hline Yes & 50 & 4.0 & $(2)$ & 1.89 & $.41-8.84$ & .417 & 14 & (7) & 6.63 & $2.44-18.02$ & .001 \\
\hline \multicolumn{12}{|l|}{ Group norms $\rrbracket^{* *}$} \\
\hline No DSH between T1-T2 & 469 & 4.52 & $(1.23)$ & 1.00 & & & 4.52 & $(1.23)$ & 1.00 & & \\
\hline DSH between T1-T2 & 31 & 5.67 & $(2.17)$ & 1.36 & $1.09-1.68$ & .005 & 6.31 & (3.97) & 1.44 & $1.20-1.73$ & .001 \\
\hline \multicolumn{12}{|l|}{ Mean $(S D)$ depression $\mathbb{1}$} \\
\hline No DSH between T1-T2 & 469 & 3.51 & $(2.34)$ & 1.00 & & & 3.51 & $(2.34)$ & 1.00 & & \\
\hline DSH between T1-T2 & 31 & 5.23 & $(4.22)$ & 1.24 & $1.05-1.46$ & .013 & 6.18 & $(4.22)$ & 1.33 & $1.15-1.53$ & .001 \\
\hline \multicolumn{12}{|l|}{ Mean (SD) anxiety } \\
\hline No DSH between T1-T2 & 469 & 7.50 & $(3.23)$ & 1.00 & & & 7.50 & $(3.23)$ & 1.00 & & \\
\hline DSH between T1-T2 & 31 & 9.85 & $(2.74)$ & 1.24 & $1.05-1.46$ & .011 & 12.44 & $+(3.24)$ & 1.55 & $1.32-1.81$ & .001 \\
\hline \multicolumn{12}{|l|}{ Mean (SD) impulsivity } \\
\hline No DSH between T1-T2 & 469 & 7.97 & $(2.80)$ & 1.00 & & & 7.97 & $(2.80)$ & 1.00 & & \\
\hline DSH between T1-T2 & 31 & 9.19 & $(3.05)$ & 1.16 & $.96-1.40$ & .128 & 8.81 & $(3.15)$ & 1.11 & $.94-1.31$ & .215 \\
\hline \multicolumn{12}{|l|}{ Mean $(S D)$ self-esteem } \\
\hline No DSH between T1-T2 & 469 & 15.87 & $(3.36)$ & 1.00 & & & 15.87 & $7 \quad(3.36)$ & 1.00 & & \\
\hline DSH between T1-T2 & 31 & 13.92 & $(3.33)$ & .85 & $.73-\quad .99$ & .04 & 10.77 & $7 \quad(4.77)$ & .68 & $.58-\quad .78$ & .001 \\
\hline \multicolumn{12}{|l|}{ Mean $(S D)$ optimism } \\
\hline No DSH between T1-T2 & 469 & 19.67 & $(3.88)$ & 1.00 & & & 19.67 & $7 \quad(3.88)$ & 1.00 & & \\
\hline DSH between T1-T2 & 31 & 19.17 & $(5.78)$ & .97 & $.84-1.11$ & .650 & 16.00 & $(5.78)$ & .80 & $.71-\quad .90$ & .001 \\
\hline \multicolumn{12}{|l|}{$\begin{array}{l}\text { Mean }(S D) \text { social } \\
\text { perfectionism } \mathbb{I}\end{array}$} \\
\hline No DSH between T1-T2 & 4692 & 26.11 & $(7.74)$ & 1.00 & & & 26.11 & $(7.74)$ & 1.00 & & \\
\hline DSH between T1-T2 & 312 & 27.31 & $(7.98)$ & 1.02 & $.95-1.09$ & .587 & 29.72 & $(10.35)$ & 1.06 & $1.00-1.12$ & .058 \\
\hline
\end{tabular}

Note. All of the odds ratios represent the increase risk of self-harming between T1 and T2 compared to those who did not report self-harm between Time 1 and Time $2(N=469)$

*Lifetime prevalence

†In a typical week, are cigarettes smoked

$\ddagger$ In a typical week, are alcoholic drinks taken

\$Past year prevalence

$\mathbb{I}$ Odds ratio for 1 point increase in score. Higher scores indicate higher depression, anxiety, impulsivity, selfesteem, optimism, and social perfectionism

${ }^{* *}$ Higher scores indicate more positive group norms for deliberate self-harm

Bold denotes statistical significance

friends who have self-harmed and their group norms for self-harm were more accepting of self-harm compared to nonselfharmers. At Time 1, the repeaters reported significantly higher levels of depression and anxiety, and lower levels of optimism and self-esteem compared to those who had not self-harmed. 


\section{MULTIVARIATE ANALYSIS}

The multivariate logistic analyses showed that the following factors were independently associated with repeat DSH: worries about sexual orientation, history of sexual abuse, self-harm by family, anxiety and self-esteem (see Table 2). History of sexual abuse was the only variable to be independently associated with first-time DSH.

\section{DISCUSSION}

This study yielded evidence in support of our two aims, to determine the prevalence of DSH prospectively over a six-month period and to investigate the factors associated with prospective DSH. Six percent of the adolescents self-harmed within the six-month duration of the study and the majority of those $(58 \%, n=18)$ were repeat self-harmers and female $(65 \%, n=20)$. The six month prevalence fits with the 12 month retrospective DSH figures found in our larger sample in Scotland (9.7\%; O'Connor, Rasmussen, et al., 2009) and those reported by adolescents in England (8.6\%; Hawton et al., 2002). Although many of the study variables predicted DSH repetition in the univariate analyses, the independent predictors of repetition in the multivariate analyses were worries about

TABLE 2

Multivariate Multinomial Logistic Regression Analyses of the Association of DSH Status (i.e., First-Time Self-Harmers $(\mathrm{N}=13)$ and Repeat Self-Harmers $(\mathrm{N}=18)$ Versus Those Who Did Not Report DSH Between Time 1 and Time 2, $\mathrm{N}=469$ ) and the Other Variables ${ }^{a}$

\begin{tabular}{|c|c|c|c|c|c|c|}
\hline & \multicolumn{3}{|c|}{$\begin{array}{c}\text { First-time DSH versus No DSH } \\
\text { between T1 and T2 }\end{array}$} & \multicolumn{3}{|c|}{$\begin{array}{l}\text { Repeat DSH versus No DSH } \\
\text { between T1 and T2 }\end{array}$} \\
\hline & $\begin{array}{l}\text { Odds } \\
\text { ratio }\end{array}$ & $95 \%$ CI & $P$ value & $\begin{array}{l}\text { Odds } \\
\text { ratio }\end{array}$ & $95 \%$ CI & $P$ value \\
\hline \multicolumn{7}{|c|}{ Sexual orientation worries* } \\
\hline No & 1.00 & & & 1.00 & & \\
\hline Yes & 1.06 & $.12-9.56$ & .961 & 4.82 & $1.25-18.52$ & .022 \\
\hline \multicolumn{7}{|l|}{ Sexual abuse* } \\
\hline No & 1.00 & & & 1.00 & & \\
\hline Yes & 7.19 & $1.18-43.96$ & .033 & 5.26 & $1.01-27.48$ & .049 \\
\hline \multicolumn{7}{|c|}{ Self-harm by family* } \\
\hline No & 1.00 & & & 1.00 & & \\
\hline Yes & 1.40 & $.286-6.84$ & .680 & 4.75 & $1.46-15.47$ & .010 \\
\hline AnxietyII & 1.17 & $.96-1.42$ & .126 & 1.30 & $1.06-1.59$ & .011 \\
\hline Self-esteem II & .94 & $.79-1.13$ & .51 & .82 & $.69-.98$ & .033 \\
\hline
\end{tabular}

Note. All of the odds ratios represent the increase risk of self-harming between T1 and T2 compared to those who did not report self-harm between Time 1 and Time $2(N=469)$

${ }^{a}$ Selection of variables for input into multivariate regression was limited to those variables associated with DSH at $p<.001$

${ }^{*}$ Lifetime prevalence

†In a typical week, are cigarettes smoked

$\ddagger$ In a typical week, are alcoholic drinks taken

$\$$ Past year prevalence

IOdds ratio for 1 point increase in score. Higher scores indicate higher depression, anxiety, impulsivity, self-esteem, optimism, and social perfectionism

${ }^{* *}$ Higher scores indicate more positive group norms for deliberate self-harm

Bold denotes statistical significance 
sexual orientation, history of sexual abuse, self-harm by family, anxiety, and self-esteem. History of sexual abuse was the only variable to emerge as an independent predictor of first-time DSH.

There is a growing corpus of research, supported by the present findings, which highlights that a history of sexual abuse is implicated in the etiology and maintenance of DSH (Cyr, McDuff, Wright, Thériault, \& Cinq-Mars, 2005; Coll, Law, Tobias, Hawton, \& Tomàs, 2001; Evans, Hawton, \& Rodham, 2005; Romans, Martin, Anderson, Herbison, \& Mullen, 1995). Previous clinical and nonclinical studies have identified child/adolescent sexual abuse as a particularly potent component of childhood adversity (Harrington et al., 2006). However, the extent of the relationship between childhood sexual abuse and nonsuicidal self-injurious behavior has recently been questioned by Klonsky and Moyer (2008), whose meta-analysis only yielded evidence for a modest association between the two. In terms of mechanisms of effect, recent research suggests that overgeneral autobiographical memory biases (which are associated with reduced social problemsolving capacity; Pollock \& Williams, 2002) and post-traumatic stress may mediate the association between childhood sexual abuse and DSH (Sinclair, Crane, Hawton, \& Williams, 2007; Weierich \& Nock, 2008). However, more research is required to explore, in detail, other potential mechanisms in the sexual abuse-DSH relationship. For example, Klonsky and Moyer (2008) suggest that this relationship may be because they share the same psychiatric risk factors. How schools respond to adolescent concerns about sexual orientation also requires careful management. Similar to work elsewhere (e.g., Fergusson, Horwood, \& Beautrais, 1999; Skegg, Nada-Raja, Dickson, Paul, \& Williams, 2003), adolescents who had reported sexual orientation concerns at baseline in our study were significantly more likely to engage in repeat DSH during the study period.

Consistent with the findings from our larger Scottish cross-sectional sample (O'Connor, Rasmussen, et al., 2009) and diathesis- stress perspectives (e.g., Joiner \& Rudd, 1995) and the Theory of Planned Behavior (Ajzen, 1991), social influence factors and psychosocial stressors had powerful predictive effects. Interestingly, although self-harm by family and friends were both predictive of repeat DSH in the univariate analyses, only family DSH emerged as a risk factor in the multivariate analyses. What is more, selfharm by family and friends were both independent predictors of DSH in our larger cross-sectional DSH survey (O'Connor, Rasmussen, et al., 2009), and self-harm by friends (not family) was a key factor associated with DSH among adolescents in England (Hawton et al., 2002). This apparent weaker influence of self-harm by friends in the present study may be a statistical artefact accounted for by the shared variance with the group norms variable or it may be that family DSH is a better predictor of repeat DSH. Nevertheless, the family DSH effect is consistent with the familial intergenerational transmission of suicide risk hypothesis (Melhem et al., 2007). Future research should endeavor, therefore, to tease out the relative influence of friends and family to determine whether differential effects exist in the prediction of first-time and repeat DSH.

Two further implications of this study are important to note: First, the findings highlight that DSH is a real issue for young people and that a significant minority may (re)commence self-harming during the course of an academic year. Although the etiology may be complex, our findings highlight some of the psychological and psychosocial risk factors associated with short-term prospective DSH. Second, related to the mechanisms of effect issues outlined above, the study raises a number of theoretical, conceptual, and practical questions. For example, how many of the so-called DSH risk factors are indeed causal in nature and how many are statistical artefacts-accounted for by the shared variance of a hidden, third factor? To this end, more prospective, experimentaltype research studies are required to tease out the complex causal pathways to DSH.

Although this study had a number of 
strengths, three notable limitations are worthy of comment. The duration of the followup was quite brief, the number of cases (i.e., those who self-harmed between Time 1 and Time 2) was relatively small and the $68 \%$ follow-up rate was relatively low for a community-based sample. As a consequence we can make no comment about the longer-term predictive utility of the variables and we can make few conclusions about the first-time self-harmers. Without question, a much larger sample would be required to tease out predictors with small effect sizes. Indeed, it would be of particular interest to investigate the differences between first-timers and repeaters in a larger sample. Although the follow-up rate was lower than what we would have liked, those who were followed up had a broadly similar psychological profile to those who were not. What is more, the significantly lower levels of impulsivity among those who completed Time 2 versus those who did not may account for the unexpected absence of a relationship between impulsivity and prospective DSH. Future research should also investigate further the psychometric properties of the short form of Plut-

\section{REFERENCES}

Appleby, L., Amos, T., Doyle, U., Tomenson, B., \& Woodman, M. (1996). General practitioners and young suicides: a preventive role for primary care. British Fournal of Psychiatry, 168, $330-333$.

Addeo, R. R., Greene, A. F., \& Geisser, M. E. (1994). Construct validity of the Robson self-esteem questionnaire in a college sample. $E d$ ucational and Psychological Assessment, 54, 439-446.

AJzen, I. (1991). The theory of planned behavior. Organizational Behavior and Human Decision Processes, 50, 179-211.

Bancroft, J.H.J., Skrimshire, A. M., \& Simkin, S. (1976). The reasons people give for taking overdoses. British fournal of Psychiatry, 128 , $538-548$

Berman, A. L., Jobes, D., \& Silverman, M. M. (2005). Adolescent Suicide: Assessment and Intervention (2nd ed.). Washington, DC: American Psychological Association.

British Educational Research AssociaTION. (1992). Ethical guidelines for educational re- chik's impulsivity scale (Plutchik et al., 1989), as the internal consistency in the present sample was low. Nonetheless, the findings regarding repetition of DSH are more robust and are supported by cross-sectional and case-control studies (e.g., De Leo \& Heller, 2004; Harrington et al., 2006; Sullivan et al., 2004). In short, we would urge more longerterm and larger-scale prospective studies of adolescent DSH.

Assuming that the risk factors are causal, the present findings suggest that school-based interventions aimed at improving self-esteem and reducing anxiety may be fruitful, and they may protect against repeat self-harm especially among females. More broadly, schools may want to consider whole school approaches to mental health and initiatives which highlight optimal coping strategies in response to psychosocial stressors including sexual abuse, family self-harm as well as anxiety and concerns about sexual orientation. The findings of this short-term prospective study could also inform screening programs to aid teachers in the identification of those at risk.

search. Nottingham, UK: British Educational Research Association.

British Psychological Society. (2004). Guidelines for minimum standards of ethical approval in psychological research. Leicester, UK: British Psychological Society.

BJelland, I., Dahl, A. A., Haug, T. T., \& Neckelmann, D. (2002). The validity of the hospital anxiety and depression scale. An updated literature review. Fournal of Psychosomatic Research, $52,69-77$.

Carter, G., Reith, D. M., Whyte, I. M., \& McPherson, M. (2005). Repeated self-poisoning: Increasing severity of self-harm as a predictor of subsequent suicide. British Fournal of Psychiatry, $186,253-257$.

Centers for Disease Control and Prevention. (2004). Youth risk behavior surveillance-United States, 2003. Morbidity and Mortality Weekly Report 53. Atlanta, USA: CDC.

Choquet, M., \& Ledoux, S. (1994). Adolescents: Enqute nationale. Paris: Institute national ol de la Santé et de la recherche médicle. 
Coll, X., Law, F., Tobías, A., Hawton, K., \& Toмàs, J. (2001). Abuse and deliberate selfpoisoning in women: A matched case-control study. Child Abuse and Neglect, 25, 1291-302.

Cyr, M., McDuff, P., Wright, J., Thériault, C., \& Cinq-Mars, C. (2005). Clinical correlates and repetition of self-harming behaviors among female adolescent victims of sexual abuse. Fournal of Child Sexual Abuse, 14, 49-68.

De Leo, D., \& Heller, T. S. (2004). Who are the kids who self-harm? An Australian selfreport school survey. Medical Fournal of Australia, 181, 140-141.

Evans, E., Hawton, K., \& Rodham, K. (2005). Suicidal phenomena and abuse in adolescents: A review of epidemiological studies. Child Abuse \& Neglect, 9, 45-58.

Fergusson, D. M., Horwood, L. J., \& Beautrais, A. L. (1999). Is sexual orientation related to mental health problems and suicidality in young people? Archives of General Psychiatry, 56 , 876-880.

Fergusson, D. M., Horwood, L. J., Ridder, E. M., \& Beautrais, A. L. (2005). Suicidal behaviour in adolescence and subsequent mental health outcomes in young adulthood. Psychological Medicine, 35, 983-993.

Flett, G. L., Hewitt, P. L., Boucher, D. J., Davidson, L. A., \& Munro, Y. (1997). The child-adolescent perfectionism scale: Development, validation, and association with adjustment. Unpublished manuscript.

Garrison, C. Z., McKeown, R. E., Valois, R. F., \& Vincent, M. L. (1993). Aggression, substance use, and suicidal behaviours in high school students. American fournal of Public Health, 83, 179-184.

Goldacre, M., \& Hawton, K. (1985). Repetition of self-poisoning and subsequent death in adolescents who take overdoses. British fournal of Psychiatry, 146, 486-489.

Harrington, R., Pickles, A., Aglan, A., Harrington, V., Burroughs, H., \& Kerfoot, $M$. (2006). Early adult outcomes of adolescents who deliberately poisoned themselves. Fournal of the American Academy of Child and Adolescent Psychiatry, $45,37-45$.

Harriss, L., Hawton, K., \& Zahl, D. (2005). Value of measuring suicidal intent in the assessment of people attending hospital following self-poisoning or self-injury. British Zournal of Psychiatry, 186, 60-66.

Hawton, K., \& FAgG, J. (1988). Suicide and other causes of death following attempted suicide. British Fournal of Psychiatry, 161, 816-823.

Hawton, K., Houston, K., \& Shepperd, R. (1999). Suicide in young people: Study of 174 cases, aged under 25 years, based on coroners and medical records. British Fournal of Psychiatry, 175, 271-276.
Hawton, K., Rodham, K., \& Evans, E. (2006). By their own hand. Deliberate self-harm and suicidal ideas in adolescents. London, UK: Jessica Kingsley Publishers.

Hawton, K., Rodham, K., Evans, E., \& Weatherall, R. (2002). Deliberate self-harm in adolescents: Self-report survey in schools in England. British Medical fournal, 325, 1207-1211.

Hawton, K., Zahl, D., \& Weatherall, R. (2003). Suicide following self-harm: Long-term follow-up of patients who presented to a general hospital. British Fournal of Psychiatry, 182, 537542 .

HJelmeland, H., Hawton, K., Nordvik, H., Bille-Brahe, U., De Leo, D., Fekete, S. et AL. (2002). Why people engage in parasuicide: A cross-cultural study of intentions. Suicide and LifeThreatening Behavior, 32, 380-393

JoIner, T. E., \& Rudd, M. D. (1995). Negative attributional style for interpersonal events and the occurrence of severe interpersonal disruptions as predictors of self-reported ideation. Suicide and Life-Threatening Behavior, 25, 297-304.

Kann, L., Kinchen, S. A., Williams, B. I., Ross, J. G., Lowry, R., Grunbaum, J. A., \& Kolbe, L. J. (2000). Youth risk behaviour surveillance. United States, 1999. Morbidity and Mortality Weekly Report, 49, 1-96.

Klonsky, E. D., \& Moyer, A. (2008). Childhood sexual abuse and non-suicidal selfinjury: Meta-analysis. British Fournal of Psychiatry, 192, 166-170.

Melhem, N. M., Brent, D. A., Ziegler, M., Iyengar, S., Kolko, D. Oquendo, M. et al. (2007). Familial pathways to early onset suicidal behavior: Familial and individual antecedents of suicidal behavior. American Fournal of Psychiatry, 164, 1364-1370.

Meltzer, H., Harrington, R., Goodman, R., \& Jenkins, R. (2001). Children and adolescents who try to harm, burt, or kill themselves. London: Office for National Statistics.

O'Connor, R. C. (2007). The relations between perfectionism and suicidality: A systematic review. Suicide and Life-Threatening Behavior, 37, 698-714.

O’Connor R. C., Armitage C. J., \& Gray, L. (2006). The role of clinical and social cognitive variables in parasuicide. British Fournal of Clinical Psychology, 45, 465-481.

O'Connor, R. C., \& Cassidy, C. (2007). Predicting hopelessness: The interaction between optimism/pessimism and specific future expectancies. Cognition and Emotion, 21, 596-613.

O'Connor, R. C., Dixon, D., \& RasmusSEN, S. (2009). The structure and temporal stability of the child and adolescent perfectionism scale. Fournal of Psychological Assessment, 00, 000-000.

O’Connor, R. C., Rasmussen, S. A., Miles, J., \& Hawton, K. (2008). Deliberate self- 
harm in adolescents. British Fournal of Psychiatry, 194, 68-72.

O'Connor, R. C., Sheehy, N. P. \& O'Connor, D. B. (1999). The classification of completed suicide into sub-types. Fournal of Mental Health, 8, 629-637.

O'Loughlin, S., \& Sherwood, J. (2005). A 20-year review of trends in deliberate self-harm in a British town, 1981-2000. Social Psychiatry and Psychiatric Epidemiology, 40, 446-453.

Plutchick, R., van Praag, H. M., Picard S., Conte, H. R., \& Korn, M. (1989). Is there a relation between the seriousness of suicidal intent and the lethality of the suicide attempt? Psychiatry Research, 27, 71-79.

Pollock, L. R., \& Williams, J.M.G. (2002). Effective problem-solving in suicide attempters depends on specific autobiographical recall. Suicide and Life-Threatening Behavior, 31, 386-396.

Robson, P. (1989). Development of a new self-report questionnaire to measure self-esteem. Psychological Medicine, 19, 513-518.

Romans, S. E., Martin, J. L., Anderson, J. C., Herbison, G. P., \& Mullen, P. E. (1995). Sexual abuse in childhood and deliberate selfharm. American Fournal of Psychiatry, 152, 13361342.

Scheier, M. F., \& Carver, C. S. (1985). Optimism, coping and health: Assessment and implications of generalized outcome expectancies. Health Psychology, 4, 219-247.

Scheier, M. F., Carver, C. S., \& Bridges, M. W. (1994). Distinguishing optimism from neuroticism (and trait anxiety, self-mastery, and self-esteem): A re-evaluation of the life orientation test. Fournal of Personality and Social Psychology, 67, 1063-1078.

Schmidtke, A., Bille Brahe, U., De Leo, D., Kerkhof, A., Bjerke, T., Crepet, P. et al. (1996). Attempted suicide in Europe: rates, trends and sociodemographic characteristics of suicide attempters during the period 1989-1992. Results of the WHO/EURO multicentre study on parasuicide. Acta Psychiatrica Scandinavica, 93, 327-338.

Silverman, M. M., Berman, A. L., Sanddal, N. D., O'Carroll, P. W., \& Joiner, T. E. (2007a). Rebuilding the Tower of Babel: A revised nomenclature for the study of suicide and suicidal behaviors. Part 1: Background, rationale, and methodology. Suicide and Life-Threatening Behavior, 37, 248-263.

Silverman, M. M., Berman, A. L., Sanddal, N. D., O'Carroll, P. W., \& Joiner, T. E. (2007b). Rebuilding the Tower of Babel: A revised nomenclature for the study of suicide and suicidal behaviors. Part 2: Suicide-related ideations, communications and behaviors. Suicide and Life-Threatening Behavior, 37, 264-277.

Sinclair J. M., Crane, C., Hawton, K., \& Williams, J. M. (2007). The role of autobiographical memory specificity in deliberate selfharm: correlates and consequences. Fournal of Affective Disorders, 102, 11-18.

SkegG, K., Nada-Raja, S., Dickson, N., Paul, C., \& Williams, S. (2003). Sexual orientation and self-harm in men and women. American Fournal of Psychiatry, 160, 541-546.

Sourander, A., Helstela, L., Haavisto, A., \& Bergroth, L. (2001). Suicidal thoughts and attempts among adolescents: A longitudinal 8year follow-up study. Fournal of Affective Disorders, 63, 59-66.

Sullivan, C., Arensman, E., Keeley, H. S., Corcoran, P., \& Perry, I. J. (2004). Young people's mental health: A report of the results from the Lifestyle and Coping Survey. Cork, Ireland: National Suicide Foundation.

Weierich, M. R., \& Nock, M. K. (2008). Posttraumatic stress symptoms mediate the relation between childhood sexual abuse and nonsuicidal self-injury. Fournal of Consulting and Clinical Psychology, 76, 39-44.

White. D., Leach, R., Sims, R., Atrinson, M., \& Cottrell, D. (1999). Validation of the hospital anxiety and depression scale for use with adolescents. British Journal of Psychiatry, 175, 452-454.

Ystgaard, M., Reinholdt, N. P., Husbym J., \& Menlum, L. (2003). Deliberate self-harm in adolescents. Tidsskrift for Den Norske Laegeforening (Norwegian Medical Fournal), 123, 2241-2245.

Zigmond, A. S., \& SNAith, R. P. (1983). The hospital anxiety and depression scale. Acta Psychiatrica Scandinavica, 67, 361-370.

Manuscript Received: January 28, 2008 Revision Accepted: August 2, 2008 